\title{
How do environmental regulations affect industrial dynamics? Evidence from China's pollution-intensive industries
}

\author{
Yi Zhou, \\ College of Urban and Environmental Sciences, Peking University, Beijing 100871, China; \\ Lincoln Institute Center for Urban Development and Land Policy, Peking University \\ Phone: (86)10-6275-7075
}

\section{Shengjun Zhu}

College of Urban and Environmental Sciences, Peking University, Beijing 100871, China;

\section{Canfei $\mathrm{He}^{1}$}

College of Urban and Environmental Sciences, Peking University, Beijing 100871, China; Lincoln Institute Center for Urban Development and Land Policy, Peking University Phone: (86)10-6275-7075

hecanfei@urban.pku.edu.cn

Acknowledgement: This work was supported by the National Science Foundation of China under Grant No. 41425001 and No. 41271130.

${ }^{1}$ Corresponding Author 


\title{
How do environmental regulations affect industrial dynamics? Evidence from China's pollution-intensive industries
}

\begin{abstract}
:
Pollution haven hypothesis $(\mathrm{PHH})$ and porter hypothesis $(\mathrm{PH})$ offer two different perspectives to understand the relationship between industrial dynamics and environmental regulations. This paper seeks to move beyond existing studies that are based on either the PHH or the PH while neglecting the other, towards an analytical framework that not only pays more attention to the ways in which the $\mathrm{PHH}$ and the PH co-exist, but also acknowledges the role of firm heterogeneity and local government intervention. Based on a firm-level industrial dataset and a dataset on China's polluting firms, this paper studies the relationship between environmental regulations and industrial dynamics in China's pollution-intensive industries at the firm level. Empirical results confirm the co-existence of the $\mathrm{PH}$ and the PHH. Furthermore, firm heterogeneity and government intervention both have the potential to inflect the relationship between environmental regulations and industrial dynamics.
\end{abstract}

\section{Keywords:}

Environmental regulation, Pollution Haven Hypothesis, Porter Hypothesis, Firm heterogeneity, government intervention

\section{Introduction}

One of the key challenges facing pollution-intensive firms is how to respond to environmental regulations (Tole and Koop 2010; List et al. 2003; Jeppesen, List, and Folmer 2002; Yang and He 2015). The existing literatures on environmental regulations and industrial dynamics pay attention to firm behaviors, firm competitiveness and their relationship with environmental regulations, based on either the Pollution Haven Hypothesis (PHH) or the Porter Hypothesis (PH) (Kearsley and Riddel 2010; Bommer 1999; Ambec et al. 2013). PHH suggests that uneven environmental regulations between countries/regions cause the relocation of pollution-intensive production to countries/regions where regulations are less strict (Birdsall and Wheeler 1993; Copeland and Taylor 2004; Tobey 1989). It is argued that high environmental standards may cause unemployment and disinvestment due to the additional costs incurred by environmental regulations (Golombek and Raknerud 1997). In contrast, PH claims that properly designed environmental regulations can catalyze innovations, which to some extent offset compliance costs (Porter 1991; Porter and van der Linde 1995). Such an 'induced innovation' effect may lower the costs of complying with environmental standards on the one hand, and generate new competitive advantages on the other (Palmer, Oates, and Portney 1995; Kumar and Managi 2009). 
According to the $\mathrm{PH}$ and the $\mathrm{PHH}$, environmental regulations force firms to internalize their environmental costs and impact (Murty and Kumar 2003). This may either result in firms being less competitive in the market because of the additional costs required to comply with regulations, or encourage firms to upgrade their production through innovations, as explained by the $\mathrm{PH}$ and its precursor - the "induced innovation" hypothesis (Hicks 1932). However, existing studies tend to predicate on either the $\mathrm{PH}$ or the $\mathrm{PHH}$, and take a "black-or-white" attitude - testifying one hypothesis while implicitly overlooking or negating the other. Furthermore, most of the massive amount of researches done on environmental regulation and industrial restructuring have either used qualitative methods such as case studies and interviews (Zhu, He, and Liu 2014), or employed quantitative analyses analyzing industrial (re)location and upgrading at the industry level (Tole and Koop 2010). Findings based on qualitative methods could be biased and hard to generalize due to the limited sample size; the high level of aggregation in existing quantitative researches makes it hard to understand firm dynamics. This study thus contributes to these debates by stressing the $\mathrm{PH}$ and the PHH often co-exist on the one hand, and by examining the relationship between environmental regulation and industrial dynamics at the firm level on the other hand. Specifically, we focus on the restructuring of pollution-intensive firms in China, and analyze four dimensions of firm dynamics: firm entry, exit, employment and productivity change. Stringent environmental regulation incurs additional costs and thus may increase entry barriers, frighten off some firms, and lead to employment and productivity decline. However, innovation and upgrading induced by environmental regulations may enable incumbents to grow and attract newcomers.

China has received much attention due to its dramatic economic growth and the subsequent environmental deterioration since its economic reform ( $\mathrm{He}, \mathrm{Pan}$, and Yan 2012). China's high-growth, low-cost, resource-intensive development model has given rise to increasingly severe environmental pollution and degradation, particularly in its coastal regions where the Reform first started (He, Wei, and Xie 2008). In addition to such a spatial variation of environmental pollution, the stringency of environmental standards as well as the enforcement of environmental laws also differs across geographical regions (Zhang and $\mathrm{Fu} 2008$ ). With the deepening of economic reform, decentralization from the central to the local has granted local governments more autonomy, which started to take a primary responsibility for local economic development (He, Wei, and Xie 2008; He et al. 2016), resulting in the so-called "decentralized authoritarianism" in terms of economic development and, more importantly, of the enforcement of environmental laws (Zhu, He, and Liu 2014). Specifically, in some wealthy regions with more severe environmental issues and higher environmental awareness amongst stakeholders, local administrations may thus enforce environmental laws more wholeheartedly, whereas local states in less developed regions that face lower level of pollution may favor economic development and implement environmental policies less genuinely (Wang and Wheeler 2005). 
This paper explores the relationship between environmental regulation and industrial dynamics in China - a country characterized by enormous spatial variation of environmental pollution on the one hand, and variegated governance structure with respect to environmental regulations on the other hand. It does so by testifying the $\mathrm{PH}$ and the PHH at the firm level and by taking into account two key factors that have been largely overlooked in recent literature - firm heterogeneity and government intervention. The next section proposes an analytical framework. In section three, we introduce data and provide some descriptive analyses. After interpreting the model and variables, section four also analyzes empirical results. The last section summarizes the main findings.

\section{Environmental regulation and industrial dynamics: the role of firm heterogeneity and government intervention}

Based on either the $\mathrm{PHH}$ or the $\mathrm{PH}$, plenty of researches have already explored the articulation between industrial dynamics and environmental regulations, but empirical evidence is at best mixed and inconclusive (Jeppesen and Folmer 2014; Murty and Kumar 2003; Zhu, He, and Liu 2014). One of the reasons is the role of firm heterogeneity has been largely overlooked. As argued by Zhu, He, and Liu (2014), even though the introduction of appropriate environmental policies may trigger industrial innovations and open up new market opportunities, both the PH and its precursor "induced innovation" hypothesis fail to include a discussion with respect to the underlying mechanisms of the introduction of innovations and to the actual availability of additional resources that innovations demand (e.g., investments, technological and technical know-how). In most studies on the $\mathrm{PH}$ and the $\mathrm{PHH}$, there is an implicit assumption that firms are homogenous. Martin (2010) has, however, pointed out that regional economic systems are often complex, consisting of numerous heterogeneous firms with different competences, technologies, business models and resources, though the firms may all belong to the same industry. Given this, it would be problematic to examine the relationship between environmental regulation and industrial dynamics without taking into account firm heterogeneity as well as whether some firms face greater pollution abatement costs or possess more resources to innovate than others.

Firm characteristics may inflect the relationship between environmental regulations and industrial dynamics in many ways (Dean, Brown, and Stango 2000; Wang and Jin 2006). Specifically, some empirical studies have stressed firm size as a key explanatory factor in regional industrial dynamics under increasingly stringent environmental regulation (Heyes 2009; Dean, Brown, and Stango 2000). Dean et al. (2000) have argued that unit pollution abatement costs may be different for small and large firms due to compliance, enforcement, and statutory asymmetries. First, compliance asymmetries result from productive and administrative economies of scale in pollution abatement activities, even regulations are equally applied and enforced across small and large firms (Pashigian 1984). Since compliance is often 
capital-intensive and demands additional investments such as those on the installation of equipment, the optimal firm size tends to increase. Firms larger than the optimal size are more capable to take pollution reduction measures appropriate to their scales of operations, whereas small firms are not resourceful enough to deal with the technology-forcing aspects of environmental laws (Dean, Brown, and Stango 2000). Furthermore, the cost of interpreting and discovering relevant laws and regulations, coping with regulatory organizations, and performing necessary paperwork could generate another type of fixed costs. Small firms again may be disadvantaged since they are not able to spread such administrative costs over high production volumes.

Second, regulations may be enforced unequally across small and large firms, resulting in enforcement asymmetries. Theoretical arguments and empirical studies however generate mixed evidence. On the one hand, large firms, particularly those with brand names, have quickly become the targets not only for national and local governments but also for campaigns by activists and social groups that are intended to improve environmental conditions(Zhang et al. 2008; Vogel 2003). The rationale behind this is to identify the most profitable and visible branded firms in the market, not because the environmental standards adopted by such firms are the worst (actually, they are often relatively good), but rather because these firms have to protect their brand reputation with consumers (Walker, Di Sisto, and McBain 2008; Zhang et al. 2008). On the other hand, other studies believe that enforcement asymmetries may occur in the opposite direction, favoring rather than penalizing large establishments (Bartel and Thomas 1987). Since enforcement agencies seek to maximize net political support, large firms often have an advantage in defending themselves with greater legal and political resources, and are therefore subjected to less stringent enforcement. Third, statutory asymmetries may be due to differences in the stringency of legislation that small firms face compared with large ones. This type of asymmetries may favor small firms since legislators tend to shield small firms form regulations to minimize the potential disproportionate effects of regulations on small businesses. In short, the impact of environmental regulation is complicated and may vary across large and small firms.

Another factor that has not received much attention in the academic literature is how local governments' intervention affects the relationship between environmental regulation and industrial dynamics. Since the initiation of China's Reform and Opening-Up Policies, China has undergone dramatic economic growth and has experienced three fundamental transformations: (1) from a state-owned, collective economy dominated by SOEs to one with growing level of private ownership and market-orientation (marketization); (2) from a centrally planned to a decentralized economy (decentralization); and (3) from a closed or partially closed economy to one increasingly integrated into the global economy (globalization) (Wei, 2001; He et al., 2008; Zhu and He, 2013). These institutional transformations have profound influences on resource mobility and (re)allocation, and thus on industrial dynamics. For instance, the state-led decentralization policies have enabled local governments to 
play a critical role in shaping regional industrial restructuring and economic development (He, Wei, and Xie 2008). High level officials in the hierarchical political system promote low level government officials based on their economic performance (Xu 2011). Even though environmental protection has been added into such a "cadre evaluation system" recently, local officials still value economic development more. Their main concern is excessively stringent environmental regulation may drive firms away from their territories, and aggressive relocation to other regions would further weaken their own plans for local industrial and economic development ( $\mathrm{Zhu}, \mathrm{He}$, and Liu 2014). As a result, local governments seek to keep firms in situ, by offering a variety of subsidies, tax credits, financial and political supports. As notified above, compliance with environmental regulations is capital-intensive and often requires the installation of equipment with high fixed costs. Government subsidies may alleviate the negative impact of compliance costs on firms, and enable the latter to adopt expensive pollution abatement technologies (e.g., waste-water treatment plants and solvent recovery systems). Subsidies can also offset administrative costs derived from changing environmental regulations, such as costs related to the interpretation of relevant regulations, and to necessary paperwork. Another type of local government effort to keep firms in situ can be seen in the establishment of industrial parks for pollution-intensive firms. Such industrial parks are often master-planned by governments with centralized waste treatment systems and other infrastructures. Wastes from all firms in the park can be collected and treated together, significantly lowering per unit treatment costs (Zhu, He, and Liu 2014). Furthermore, industrial parks are mostly located in unpopulated, remote areas with an abundance of cheap land and limited social exposure, causing little social discontents (Tao et al. 2010; Cao, Feng, and Tao 2008). Firms in parks enjoy a degree of anonymity and therefore may be able to avoid a portion of compliance costs.

Finally, firm heterogeneity and local government intervention may interconnect with one another, co-shaping the articulation between environmental regulation and industrial dynamics. Chinese central government seeks to shift from a pro-growth, pro-business development model to one oriented more towards environmental sustainability, driven to some extent by the rising environmental awareness of the public (Francesch-Huidobro, Lo, and Tang 2012). However, as notified above, local authorities do not always share the concerns that incentivize national government policies. Instead, local governments often respond to central government's ambition in different ways, resulting in increasing emphasis on environmental sustainability at the national level and segmented enforcement of environmental laws at the local level (Zhan, Lo, and Tang 2014). Specifically, in China, local environmental protection bureau (EPB) takes the primary responsibility for the enforcement of national environmental regulations and policies. Though supervised by the corresponding agency at higher administrative levels, local EPBs rely heavily on financial resources and political supports provided by local governments (Francesch-Huidobro, Lo, and Tang 2012). The enforcement of environmental laws thus could be compromised as local governments have other concerns. 
For instance, even after three decades of economic reform, China's state-owned enterprises (SOEs) still play an important role and are systematically favored by various levels of governments(Huang 2003). Local governments, whose income and promotion opportunities are tied to the development of SOEs, have vested interests which oppose the dismantling of the inefficient state-owned sector. Local governments tend to resist the rationalization of SOEs within their jurisdiction through local protectionism (e.g., subsidies, discriminatory regulation enforcement, and intervention in the market)(Zhao and Zhang 1999; Poncet 2005). Since SOEs often have a close relationship with the state and possess greater political power, local protectionism is more widespread in SOEs-dominated industries. The strong bargaining power SOEs have may lessen the deterrent impact of regulations on themselves, whereas non-SOEs are more closely scrutinized and face stricter enforcement (Wang and Jin 2002; Wang et al. 2003). Another characteristic of China's post-reform institutional landscape is the systematic misallocation of financial resources. Private firms often face greater credit constraints whereas SOEs have received the majority of government lending and investment funds. Similarly, driven by the "grasp the large, let go the small" policy, Chinese governments often favor large, key firms that have potentials to generate massive jobs and profits, whereas small enterprises, particularly those pollution-intensive ones, have been at times neglected by the central and local authorities (Sutherland 2003). Like SOEs, large firms may also enjoy reduced obligations to comply with regulations, have better access to finance and softer budget constraints, and therefore may be less affected by changing environmental policies.

\section{Data source and the dynamics of China's pollution-intensive industries}

\subsection{Data source}

This paper uses the China's Annual Survey of Industrial Firms (ASIF). The dataset is maintained by China's National Bureau of Statistics and covers (1) all industrial SOEs and (2) non-SOEs with an annual sale higher than 5 million RMB. It offers firm-level data on firm names, legal person, year of birth, location, capital structure, total profits, employment, etc. We define firm exit and entry as follows. If firm $i$ is included in the dataset in year $t$ but not in year $t-1$, it is assumed that in year $t$ firm $i$ enters. Similarly, if firm $i$ is reported in year $t-1$ but not in year $t$, it is seen as a firm exit.

To calculate the pollution intensity of industries, we use another dataset - Key National Monitoring Sources of Polluting Firms (KNMSPF)—issued by China's Ministry of Environmental Protection (MEP). The MEP has included over 80,000 firms in the KNMSPF list based on their major pollutant emissions - emissions of water pollutants (measured by ammonia emissions and industrial COD) and air pollutants (measured by industrial dust, soot, and industrial $\mathrm{SO}_{2}$ ) - in the previous year. All firms reported in the KNMSPF were monitored thereafter. In 2009, for 
instance, such firms accounted for $65 \%$ of total pollution emission. We match the 2009 KNMSPF list with the 2008 ASIF dataset by using legal person code and firm name. $73.6 \%$ of firms in the 2009 KNMSPF list are matched successfully.

\subsection{Dynamics of China's pollution-intensive industries}

We use the percentage of industrial $\mathrm{SO}_{2}$ meeting standard for emission in a city to measure the degree of environmental regulation stringency and the effectiveness of the enforcement of regulations in a city. Environmental policies, such as the Air Pollution Prevention and Control Law and Two Control Zones designating an acid rain control zone and a sulfur dioxide pollution control zone, are often implemented at the national level, according to which new firms that could not use low-sulfur coal were required to install desulfurization facilities or take other measure to control $\mathrm{SO}_{2}$ emissions, and existing plants were encouraged to control $\mathrm{SO}_{2}$. However, the enforcement of such policies varied across cities(Hering and Poncet 2014). The percentage of industrial $\mathrm{SO}_{2}$ meeting standard for emission in a city is thus a good proxy of local governments' attitude towards nation-wide environmental policies and the stringency of environmental regulation at the local level. Figure 1 maps out the spatial variation of this indicator in 2003 and 2008. First, environmental regulation became more stringent in most Chinese cities and the average increased from 0.218 to 0.885 from 2003-2008. Second, a simple comparison between two maps show that the degree of environmental regulation in inland cities is not significantly lower than that in coastal cities in 2003, whereas in 2008 the latter faced relatively stricter environmental regulations.
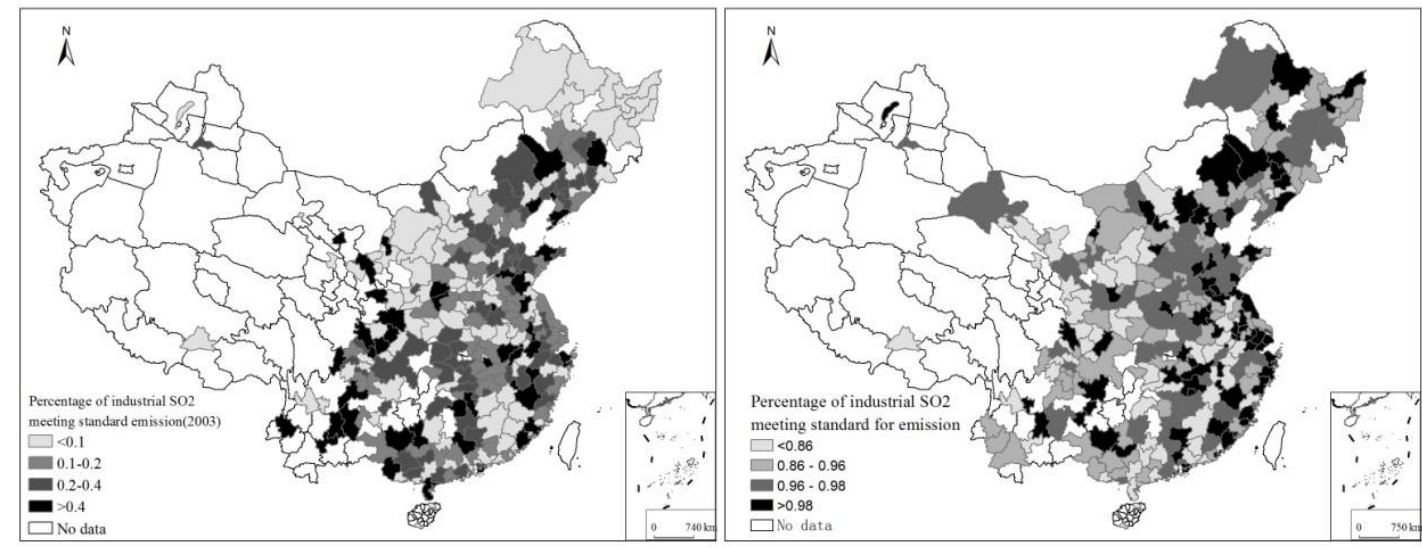

Figure 1 the percentage of industrial $\mathrm{SO}_{2}$ meeting standard for emission at the city level in 2003 (left) and 2008 (right)

We also examine the dynamics of China's pollution-intensive industries at the 4-digit level. A 4-digit industry is considered as pollution-intensive, if there are firms in this industry being included in the KNMSPF. Figure 2 shows the geography of firm entry and exit in pollution-intensive industries in two periods: 1998-2003 and 2003-2008. Firm entry rate in both periods is dramatically higher than exit rate in all 
provinces. During the first period, provinces in China's coastal region have witnessed higher entry rate, particularly Zhejiang, Shandong, Guangdong and Jiangsu. During the second period, entry rate in a number of inland provinces, such as Anhui, Chongqing, Jiangxi, Inner Mongolia, and Sichuan has increased significantly, with an entry rate as high as $180 \%$, though entry rate in some coastal provinces remains high (e.g., Liaoning, Jiangsu, Shandong and Zhejiang). These findings on the spatial and temporal dynamics of China's pollution-intensive industries also echo what is shown in Figure 1, suggesting that pollution-intensive production has been relocating from China's coastal regions with stricter environmental standard, to less developed inland provinces.

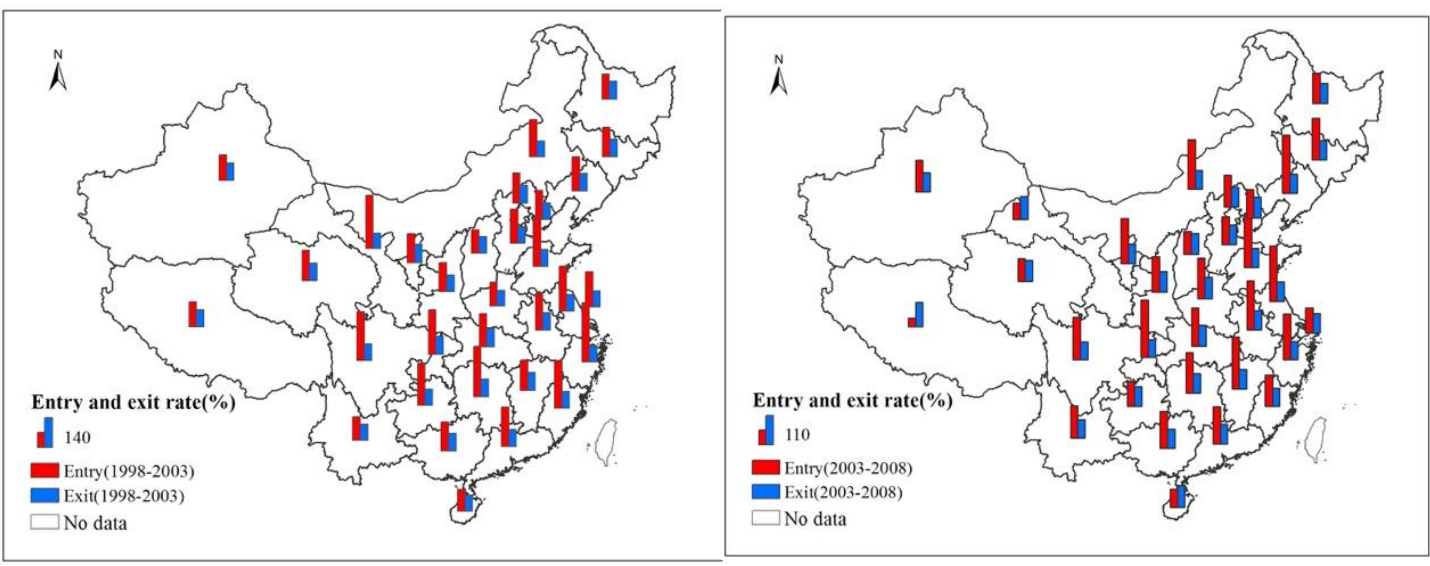

Figure 2 Firm entry and exit rate of pollution-intensive industries at the provincial level during 1998-2003 and 2003-2008

The rapid inter-regional shifts of pollution-intensive industries are also seen in the spatial and temporal evolution of incumbent firms' productivity and employment (Figure 3 and 4). We adopt the algorithm developed by Olley and Pakes (1996) to calculate firms' total factor productivity (TFP). During 1998-2003, pollution-intensive industries became increasingly concentrated in China's coastal region (Figure 3). Provinces in East China have witnessed high level of employment growth among incumbent firms, whereas most inland provinces experienced dramatic employment decline in pollution-intensive industries. However, during the second period, as environmental regulations became stricter and social pressures emerged particularly in coastal provinces where industrialization first started, the dominance of coastal cities in pollution-intensive industries was relatively weakened. Employment in a large number of inland provinces started to grow more rapidly (e.g., Shanxi, Shaanxi and Qinghai), though employment remained high in some coastal provinces. Such a two-stage geographical and industrial transformation is also evident in firms' productivity change (Figure 4). During 1998-2003, provinces in East China and some in Central China outperformed others in terms of TFP improvement. As the stringency of environmental regulations increased particularly in East China, firms in coastal provinces had to pay higher level of compliance costs and set up additional resources to cope with new policies, whereas firms in inland provinces with relatively 
less stringent regulations were able to improve their productivity more quickly. These findings support the $\mathrm{PHH}$, but within each province, the relationship between environmental regulations and firm dynamics is much more complicated, affected by firm heterogeneity and local government intervention. It is to this we now turn.
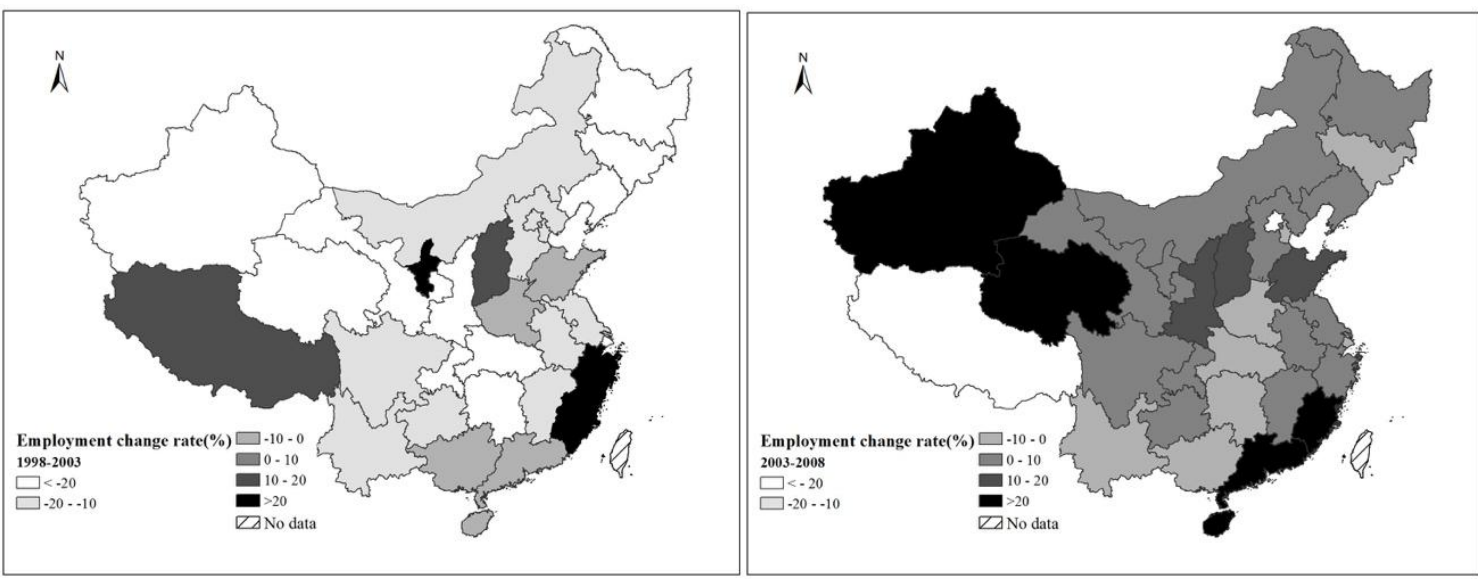

Figure 3 Employment change of incumbent firms in pollution-intensive industries at the provincial level during 1998-2003 and 2003-2008
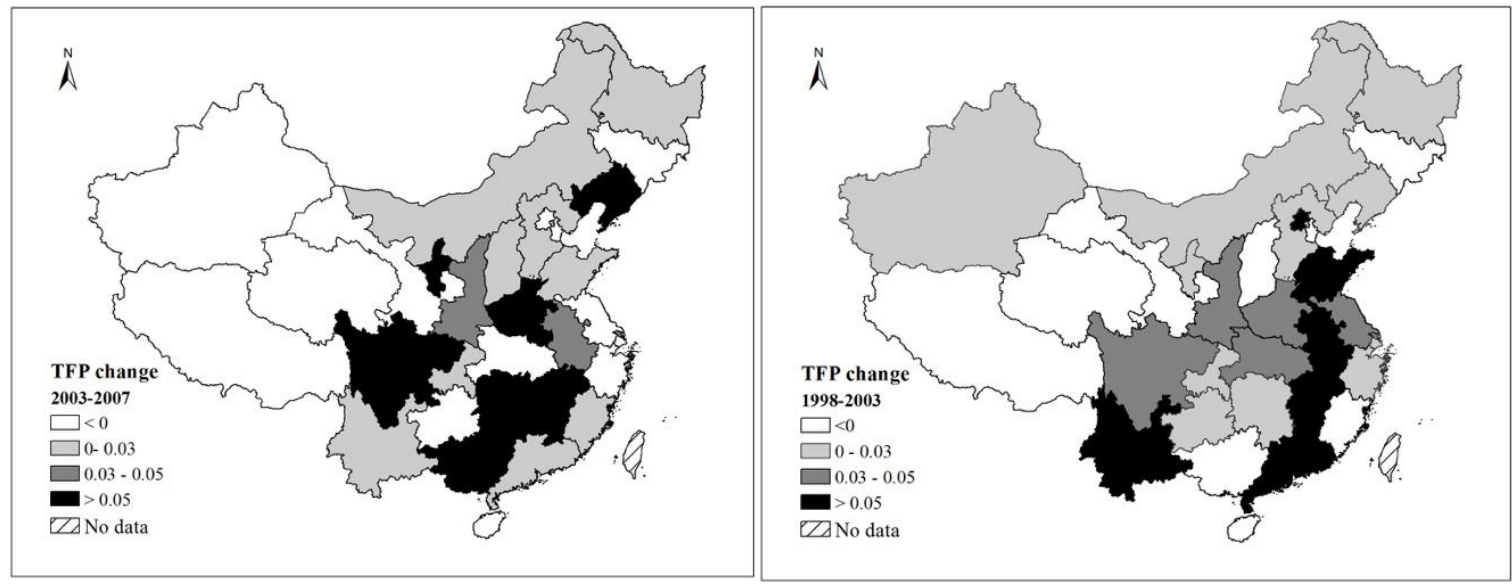

Figure 4 TFP change of incumbent firms in pollution-intensive industries at the provincial level during 1998-2003 and 2003-2008

\section{Model specification and empirical results}

\subsection{Model specification}

The following equation is estimated to investigate how firm heterogeneity and government intervention have affected the relationship between environmental regulation and industrial dynamics.

$$
\begin{aligned}
& Y_{i, t}=\beta_{0}+f_{1}\left(E R_{k, t-1} * P I_{j}\right)+f_{2}\left(F S_{i, t-1}, I S_{\mathrm{i}, t-1}\right)+f_{3}\left[\left(F S_{i, t-1}, I S_{\mathrm{i}, t-1}\right) *\right. \\
& \left.\left(E R_{k, t-1} * P I_{j}\right)\right]+X_{j, k, t-1}+w_{j}+v_{k}+u_{t}
\end{aligned}
$$


where $i, j, k$, and $t$ denote firm, industry, city, and year, respectively. Industry $j$ represents a 4-digit industry. Four dependent variables are included. Entry (or Exit) takes the value of 1 if firm $i$ is a new entrant (or exiting firm) in year $t$, and 0 otherwise. Employment and TFP are the change of employment and TFP of firm $i$ from year $t-1$ to $t$.

We use the percentage of industrial $\mathrm{SO}_{2}$ meeting standard for emission in city $k$ in year $t-1(E R)$ to measure the degree of environmental regulation stringency. Data on this variable are derived from China's City Statistical Yearbook. Pollution intensity $(P I)$ is the share of firms in industry $j$ that have been included in the KNMSPF air pollution list, indicating intrinsic exposure of industry $j$ to environmental regulations. The interaction term, $E R^{*} P I$, thus shows to what extent industry $j$ that firm $i$ belongs to is affected by environmental regulations in city $k$.

In equation (4), FS refers to firm-specific factors. The number of employees in a firm is used as a proxy of firm size $(S I Z E)$. Firm ownership structure also affects the relationship between firm dynamics and environmental regulations. Dummy variables, $S O E, F O E$ and $P O E$, are included, taking the value of 1 if the largest share of a firm's paid-in capital is state-owned, foreign-owned and privately-owned respectively, and 0 otherwise. We further include two variables on local government intervention. The ratio of the value of government subsidies a firm has received to the firm's total output value (SUBSIDY) is used to capture direct government intervention under China's regionally decentralized authoritarian system that may affect firms' capabilities in coping with environmental regulations. Finally, local governments often provide additional financial, technological and political supports, and centralized waste treatment system to firms located in government-designated industrial parks, which may lower firms' compliance costs. PARK is a dummy variable, taking the value of 1 if a firm is located in industrial parks and 0 otherwise.

$X$ represents control variables. We include the comparative advantage of industry $j$ in city $k$ and year $t-1$, measured by the location quotient $(L Q)$. Industry growth is measured as the annual growth rate of output of industry $i$ in the entire country $(G R O W)$. The Theil Index of industry $i$ in city $k$ (Theil) is calculated to reflect local industrial diversity and the degree of market competition. The average labor cost of industry $i$ and city $k(L A B)$ is added as a proxy of production cost to control the latter's impact on industrial dynamics. Finally, $w$ indicates the industry-specific effect, $v$ indicates the city-specific effect, and $u$ indicates the time-specific effect. Variable definitions and descriptive statistics are shown in Table A1.

\subsection{Empirical results}

We estimate equation (1) with the Linear Probability Model (LPM). Correlation analysis shows that correlations between variables are low, indicating no serious 
multi-collinearity problem. Table 1 reports the econometric results. In model (1) - (4) and (5) - (8), dependent variables are Entry, Exit, Employment and TFP, respectively. The dummy variable for industry (Industry in Table 1) is measured at the 2-digit level. Variable, $L Q$, has a negative and significant relationship with firm exit, indicating that the co-location of a large number of firms in the same industry generates agglomeration externalities and reduces the likelihood of firm exit. The sign of GROW's coefficient suggests that it is common to see high level of firm entry and exit, and rapid productivity improvement in industries that are in the emergence and growth phase of their lifecycle. Firms located in cities with high level of industry diversity and market competition (see the coefficients of Theil) are subject to fiercely aggressive behaviors by rivals, resulting in the co-existence of fewer entries and more exits. Intensive market competition may also have a negative impact on individual firm's innovation and productivity upgrading. High level of labor cost may frighten off new entrants. Existing firms in high-cost cities tend to downsize rather than exit. However, high labor cost is often associated with high labor quality, leading to high productivity growth.

Table 1 Empirical results

\begin{tabular}{|c|c|c|c|c|c|c|c|c|}
\hline & (1) & (2) & (3) & (4) & (5) & (6) & (7) & $(8)$ \\
\hline & Entry & Exit & growth & TFP & Entry & Exit & growth & TFP \\
\hline$E R * P I$ & $-0.121^{* * *}$ & $0.0243^{* * *}$ & $0.0613^{* * *}$ & $-0.186^{*}$ & $-0.0710^{* *}$ & $0.0604^{* * *}$ & -0.0379 & $-0.402^{* * *}$ \\
\hline$E R * P I * S I Z E$ & & & & & $0.030^{* * *}$ & $0.004^{*}$ & $0.0218^{* * *}$ & -0.0030 \\
\hline$E R * P I * S O E$ & & & & & $0.117^{* * *}$ & $-0.0889^{* * *}$ & $-0.4122^{* * *}$ & $0.494^{* * * *}$ \\
\hline$E R^{*} P I^{*} F O E$ & & & & & -0.0267 & -0.0061 & $-0.1624^{* * *}$ & $0.617^{* * *}$ \\
\hline$E R * P I * P O E$ & & & & & $-0.146^{* * *}$ & -0.0361 & $-0.0885^{* *}$ & 0.190 \\
\hline$E R * P I * P A R K$ & & & & & $0.0878^{* * *}$ & -0.0215 & 0.0510 & 0.0659 \\
\hline$E R * P I * S U B S I D Y$ & & & & & -0.109 & $0.334^{* * * *}$ & -0.0920 & $-3.548^{* * *}$ \\
\hline SIZE & $-0.131^{* * *}$ & $-0.0677^{* * *}$ & $-0.0189^{* * * *}$ & $0.0653^{* * *}$ & $-0.135^{* * *}$ & $-0.0685^{* * *}$ & $-0.0273^{* * *}$ & $0.0644^{* * *}$ \\
\hline SUBSIDY & -0.0030 & $0.020^{* * *}$ & $-0.0186^{* * *}$ & $-0.141^{* * *}$ & -0.003 & $0.020^{* * * *}$ & $-0.0185^{* * *}$ & $-0.138^{* * *}$ \\
\hline$T F P_{t-1}$ & & & $0.1189^{* * *}$ & $-0.416^{* * *}$ & & & $0.0119^{* * *}$ & $-0.415^{* * *}$ \\
\hline PARK & $0.0050^{* * *}$ & $-0.0327^{* * *}$ & $0.1063^{* * *}$ & -0.001 & $0.00317^{* * *}$ & $-0.0319^{* * *}$ & $0.0107^{* * *}$ & 0.0006 \\
\hline$L Q$ & -0.404 & $-0.822^{* * *}$ & -0.0191 & 0.097 & -0.430 & $-0.813^{* * *}$ & -0.300 & 0.742 \\
\hline Theil & $-0.0002^{* * *}$ & $0.0001^{* * *}$ & $0.008^{* *}$ & $-0.0001^{* * *}$ & $-0.0002^{* * *}$ & $0.0001^{* * *}$ & $0.008^{*}$ & $-0.0001^{* * *}$ \\
\hline$L A B$ & $-0.001^{* * *}$ & $-0.003^{* * *}$ & $-0.138^{* * *}$ & $0.350^{* * *}$ & $-0.001^{* * *}$ & $-0.003^{* * *}$ & $-0.014^{* * *}$ & $0.400^{* * *}$ \\
\hline GROW & $0.0017^{* * *}$ & $0.00003^{*}$ & -0.0017 & $0.001^{* *}$ & $0.002^{* * *}$ & $0.00003^{* *}$ & -0.0017 & $0.0004^{* *}$ \\
\hline$S O E$ & Included & Included & Included & Included & $-0.0474^{* * *}$ & $0.0263^{* * *}$ & -0.0208 & $-0.140^{* * * *}$ \\
\hline FOE & Included & Included & Included & Included & $0.0440^{* * *}$ & $-0.0585^{* * *}$ & $0.0184^{* * * *}$ & $-0.0332^{* * *}$ \\
\hline$P O E$ & Included & Included & Included & Included & $0.0941^{* * *}$ & $-0.0339^{* * * *}$ & $0.0049^{* *}$ & -0.0003 \\
\hline Industry & Included & Included & Included & Included & Included & Included & Included & Included \\
\hline Province & Included & Included & Included & Included & Included & Included & Included & Included \\
\hline Year & Included & Included & Included & Included & Included & Included & Included & Included \\
\hline _cons & $0.680^{* * *}$ & $0.177^{* * *}$ & $-0.1887^{* *}$ & $1.291^{* * *}$ & $0.609^{* * *}$ & $0.201^{\text {**** }}$ & $-0.2009^{* *}$ & $1.354^{* * *}$ \\
\hline$N$ & 1415402 & 1287349 & 905220 & 674761 & 1415426 & 1287364 & 905222 & 674761 \\
\hline$R^{2}$ & 0.195 & 0.034 & 0.004 & 0.239 & 0.197 & 0.034 & 0.007 & 0.239 \\
\hline
\end{tabular}


${ }^{*} p<0.1,{ }^{* *} p<0.05,{ }^{* * *} p<0.01$

The interaction term, $E R * P I$, has a positive (negative) effect on firm exit (entry), which is consistent with theoretical prediction. This means that if a firm belongs to pollution-intensive industries, it is more likely to exit in cities with stringent environmental regulation and less likely to enter such cities, supporting the arguments made by the PHH. Firms tend to upsize in response to stringent environmental regulation (Model 3). One possible explanation is that firms do so to be more capable of spreading compliance and administrative costs over high production volumes. High compliance and administrative costs caused by stringent environmental regulation may also have some negative impacts on firms' productivity growth (Model 4).

Since we seek to examine if the relationship between environmental regulation and firm dynamics are affected by firm heterogeneity and local government intervention, we focus on the coefficients of interaction terms between $E R^{*} P I$ and firm-specific/city-specific variables in Model 5-8. The key findings are as follows. First, even though environmental regulations have a significant impact over firm dynamics in pollution-intensive industries, their influences over large firms are relatively weaker. Specifically, in pollution-intensive industries large firms outperform small firms in terms of firm entry and employment growth in cities with strict environmental regulations, possibly due to large firms' capabilities in spreading compliance and administrative costs over high production volumes, and their strong political influence over local governments and EPBs.

Second, firms with different ownership structure are also affected by environmental regulations differently, since they have different capabilities to absorb compliance costs and different bargaining power with the regulator.

Pollution-intensive SOEs' entry and exit are impacted by environmental regulations to a lesser extent than pollution-intensive POEs and FOEs. This resonates with a number of similar studies. Dean, Lovely, and Wang (2009) suggest POEs have less bargaining power than SOEs and the latter are more capable to escape sanctions. Wang and Wheeler (2005) stress that state ownership is closely interconnected with the effective levy on firms' air pollution in China. Furthermore, model 7-8 show the other half of the story that has received less attention in recent studies. Even though pollution-intensive SOEs are more likely to downsize while facing stringent environmental regulations, what is interesting is they are more likely to innovate and upgrade than POEs. One possible explanation is SOEs have softer budget constraints and better access to financial resources, while POEs often suffer from great credit constraints (see Dollar and Wei, 2007 on the systematic misallocation of financial resources in China). Likewise, FOEs are also more capable to innovate and increase productivity, due to financial and technological supports received from their mother companies. In short, these findings based on the dynamics of certain types of firms support the PH. 
Finally, another factor contributing to the co-existence of the $\mathrm{PH}$ and the $\mathrm{PHH}$ is related to the role of government intervention at the local level. Entry of pollution-intensive firms located in government-designated industrial parks is affected by environmental regulations to a lesser extent, since infrastructure such as centralized waste treatment systems may lower firms' compliance costs. In contrast, firms receiving government subsidies are more likely to exit and less likely to upgrade, indicating that such firms are less efficient and tend to rely on government subsidies rather than innovation and industrial upgrading. The reason that two types of government intervention - industrial parks and government subsidies - have different impacts over the articulation between environmental regulations and firm dynamics is possibly because the former reflect supportive government policies and capture the "facilitating" role of local governments, whereas the latter represent direct government intervention in the form of subsidies indicating to what extent local governments play an "intervening" and hands-on role in regional economic development. Industrial parks would help foster a nurturing environment for entrepreneurial activities and reinforce knowledge spillovers, while high level of direct subsidies may discourage firms from innovating and make them become increasingly reliant on government supports.

As a robustness check, we re-estimate all models (1) by defining $E R$ as the percentage of industrial waste water meeting standard for discharge in city $k$ in year $t-1$, and $P I$ as the portion of firms in industry $j$ that have been included in the KNMSPF water pollution list; and (2) by using the number of staff in local EPB as a proxy of environmental regulation stringency in China (see Table A2) ${ }^{1}$. Compared with the results presented above, these changes produce only minor effects. Due to space limitation, these results are not reported here.

\section{Conclusion}

Recent studies on environmental regulation and industrial dynamics tend to predicates either on the $\mathrm{PH}$ or on the $\mathrm{PHH}$, and argue that environmental regulations may either render firms less competitive due to the additional costs required to comply with regulations and force them to exit or relocate, or encourage firms to upgrade their production through industrial innovations. Existing studies thus fall short in uncovering the whole picture where various interconnected factors all have potentials to inflect the relationship between environmental regulations and industrial dynamics. In addition, most researches have either adopted quantitative methods analyzing industrial dynamics at the industry and regional level, or employed qualitative analyses such as case studies. Findings from the former approach have limitations due

\footnotetext{
${ }^{1}$ This indicator has been used in some recent studies (He, Zhang, and Wang 2012; He, Huang, and Ye 2013). However, data is only available at the provincial level. We hence prefer our current indicator to this one.
} 
to the high level of aggregation, while the latter researches could be biased due to the limited sample size. This paper seeks to contribute to recent studies by examining the relationship between environmental regulation and industrial dynamics at the firm level based on both the PHH and the PH.

By combining a firm-level industrial dataset of China's manufacturing industries and a dataset on polluting firms in China, we show the co-existence of the $\mathrm{PHH}$ and the PH in China, and linking this story to two key factors that have been largely overlooked in existing studies - firm heterogeneity and government intervention. Empirical results confirm that large and politically-influential firms are in a better position to cope with increasingly stringent environmental regulations in China as they face lower per unit compliance costs. Their strong bargaining power may also lessen the deterrent impact of regulations on themselves. Thanks to softer budget constraints, reduced obligations to comply with environmental regulations, and better access to financial resources, SOEs may maintain their business and even upgrade in some cases despite the issuance of new, stricter environmental laws, whereas POEs are compelled to adjust by downsizing their production due to increased costs. Finally, facilitating local governments play a more helpful role in the development of pollution-intensive industries than intervening ones.

Theoretically, this research contributes to recent debates on the relationship between environmental regulations and industrial dynamics not only by emphasizing the co-existence of the $\mathrm{PH}$ and the $\mathrm{PHH}$, but also by bringing firm heterogeneity and local government intervention to the forefront and investigating how firms with different attributes in different cities act differently as the stringency of environmental regulations increases. Empirically, although in recent literature SOEs are often seen as having a bad reputation with respect to their environmental performance and lack of obligations to comply with regulations in China, our research shows they are actually investing in innovation in response to stringent environmental regulations. Large firms also play a critical role in China's transition towards environment-friendly development model. More importantly, local government should serve as a facilitator, whereas an "intervening" local government tends to have minor, if not negative, impacts over the sustainable development of pollution-intensive industries.

In drawing from analyses of firm-level data from 1998-2008, we realize the potential limitations of our study. First, our firm-level dataset does not enable us to examine the industrial dynamics of small firms. Nonetheless, this flaw only slightly affects research results, because a comparison with the 2004 and 2008 full census of industrial firms reveals that firms in our dataset employed roughly $70 \%$ of the industrial workforce and generated more than $90 \%$ of output and exports. Second, with an increasing number of pollution incidences, such as those hazy and foggy days in Beijing since 2013, reported by the media, more attention has been directed towards reducing pollution and to promoting clean technology in the 2010s. However, this dataset only covers the years of 1998-2008. More recent data including both 
small and large firms is needed to better understand the interaction between changing environmental regulations and industrial dynamics. Future research could also explore the mechanisms underlying the interaction between environmental regulations, industry dynamics, firm heterogeneity and government intervention by employing qualitative methods. Finally, this paper only examines the role of industrial parks and subsidies - one facet of institutional context. Other facets of regional institutions should also play a role, which we leave for future research as well.

\section{References}

Ambec, Stefan, Mark A. Cohen, Stewart Elgie, and Paul Lanoie. 2013. "The Porter Hypothesis at 20: Can Environmental Regulation Enhance Innovation and Competitiveness?" Review of Environmental Economics and Policy, January, res016. Bartel, Ann P., and Lacy Glenn Thomas. 1987. "Predation through Regulation: The Wage and Profit Effects of the Occupational Safety and Health Administration and the Environmental Protection Agency." The Journal of Law \& Economics 30 (2): 239-64. Birdsall, Nancy, and David Wheeler. 1993. "Trade Policy and Industrial Pollution in Latin America: Where Are the Pollution Havens?" The Journal of Environment \& Development 2 (1): 137-49.

Bommer, Rolf. 1999. "Environmental Policy and Industrial Competitiveness: The Pollution-Haven Hypothesis Reconsidered." Review of International Economics 7 (2): 342-55.

Cao, Guangzhong, Changchun Feng, and Ran Tao. 2008. "Local 'Land Finance' in China's Urban Expansion: Challenges and Solutions." China \& World Economy 16 (2): 19-30.

Copeland, Brian R., and M. Scott Taylor. 2004. "Trade, Growth, and the Environment." Journal of Economic Literature 42 (1): 7-71.

Dean, Judith M., Mary E. Lovely, and Hua Wang. 2009. “Are Foreign Investors Attracted to Weak Environmental Regulations? Evaluating the Evidence from China." Journal of Development Economics 90 (1): 1-13.

Dean, Thomas J., Robert L. Brown, and Victor Stango. 2000. "Environmental Regulation as a Barrier to the Formation of Small Manufacturing Establishments: A Longitudinal Examination." Journal of Environmental Economics and Management 40 (1): $56-75$.

Dollar, David, and Shang-Jin Wei. 2007. "Das (Wasted) Kapital: Firm Ownership and Investment Efficiency in China." Working Paper 13103. National Bureau of Economic Research.

Francesch-Huidobro, Maria, Carlos Wing-Hung Lo, and Shui-Yan Tang. 2012. "The Local Environmental Regulatory Regime in China: Changes in Pro-Environment Orientation, Institutional Capacity, and External Political Support in Guangzhou." Environment and Planning A 44 (10): 2493-2511.

Golombek, Rolf, and Arvid Raknerud. 1997. "Do Environmental Standards Harm Manufacturing Employment?” Scandinavian Journal of Economics 99 (1): 29-44. He, Canfei, Tianming Chen, Xiyan Mao, and Yi Zhou. 2016. "Economic Transition, 
Urbanization and Population Redistribution in China." Habitat International 51

(February): 39-47.

He, Canfei, Zhiji Huang, and Xinyue Ye. 2013. "Spatial Heterogeneity of Economic Development and Industrial Pollution in Urban China." Stochastic Environmental Research and Risk Assessment 28 (4): 767-81.

He, Canfei, Fenghua Pan, and Yan Yan. 2012. "Is Economic Transition Harmful to China's Urban Environment? Evidence from Industrial Air Pollution in Chinese Cities." Urban Studies 49 (8): 1767-90.

He, Canfei, Yehua Dennis Wei, and Xiuzhen Xie. 2008. "Globalization, Institutional Change, and Industrial Location: Economic Transition and Industrial Concentration in China." Regional Studies 42 (7): 923-45.

He, Canfei, Teng Zhang, and Rui Wang. 2012. "Air Quality in Urban China.” Eurasian Geography and Economics 53 (6): 750-71.

Hering, Laura, and Sandra Poncet. 2014. "Environmental Policy and Exports: Evidence from Chinese Cities." Journal of Environmental Economics and Management 68 (2): 296-318.

Heyes, Anthony. 2009. "Is Environmental Regulation Bad for Competition? A Survey." Journal of Regulatory Economics 36 (1): 1-28.

Hicks, J.R. 1932. The Theory of Wages. Macmillan, London. London.: Macmillan. Huang, Yasheng. 2003. "One Country, Two Systems: Foreign-Invested Enterprises and Domestic Firms in China." China Economic Review 14 (4): 404-16.

Jeppesen, Tim, and Henk Folmer. 2014. "The Confusing Relationship between Environmental Policy and Location Behaviour of Firms: A Methodological Review of Selected Case Studies.” The Annals of Regional Science 35 (4): 523-46.

Jeppesen, Tim, John A. List, and Henk Folmer. 2002. "Environmental Regulations and New Plant Location Decisions: Evidence from a Meta-Analysis." Journal of Regional Science 42 (1): 19-49.

Kearsley, Aaron, and Mary Riddel. 2010. "A Further Inquiry into the Pollution Haven Hypothesis and the Environmental Kuznets Curve." Ecological Economics, Special Section: Coevolutionary Ecological Economics: Theory and Applications, 69 (4): 905-19.

Kumar, Surender, and Shunsuke Managi. 2009. "Win-Win Opportunities and Environmental Regulation: Test of the Porter Hypothesis." In The Economics of Sustainable Development, 157-66. Natural Resource Management and Policy 32. Springer US.

List, John A., Daniel L. Millimet, Per G. Fredriksson, and W. Warren McHone. 2003. "Effects of Environmental Regulations on Manufacturing Plant Births: Evidence from a Propensity Score Matching Estimator." Review of Economics and Statistics 85 (4): 944-52.

Martin, Ron. 2010. "Roepke Lecture in Economic Geography-Rethinking Regional Path Dependence: Beyond Lock-in to Evolution." Economic Geography 86 (1): 1-27. Murty, M. N., and S. Kumar. 2003. "Win-win Opportunities and Environmental Regulation: Testing of Porter Hypothesis for Indian Manufacturing Industries." Journal of Environmental Management 67 (2): 139-44. 
Olley, G. S., and A. Pakes. 1996. "The Dynamics of Productivity in the

Telecommunications Equipment Industry.” Econometrica 64 (6): 1263-97.

Palmer, Karen, Wallace E. Oates, and Paul R. Portney. 1995. "Tightening

Environmental Standards: The Benefit-Cost or the No-Cost Paradigm?" The Journal of Economic Perspectives 9 (4): 119-32.

Pashigian, B. Peter. 1984. "Effect of Environmental Regulation on Optimal Plant Size and Factor Shares, The." Journal of Law \& Economics 27: 28.

Poncet, Sandra. 2005. "A Fragmented China: Measure and Determinants of Chinese

Domestic Market Disintegration.” Review of International Economics 13 (3): 409-30.

Porter, M. 1991. “America’s Green Strategy.” Scientific American 264 (4).

Porter, Michael E., and Claas van der Linde. 1995. "Toward a New Conception of the

Environment-Competitiveness Relationship." The Journal of Economic Perspectives 9 (4): 97-118.

Sutherland, Dylan. 2003. China's Large Enterprises and the Challenge of Late Industrialisation. Routledge.

Tao, Ran, Fubing Su, Mingxing Liu, and Guangzhong Cao. 2010. "Land Leasing and Local Public Finance in China's Regional Development: Evidence from

Prefecture-Level Cities.” Urban Studies, March.

Tobey, James A. 1989. "Economic Development and Environmental Management in the Third World." Habitat International 13 (4): 125-35.

Tole, Lise, and Gary Koop. 2010. "Do Environmental Regulations Affect the Location Decisions of Multinational Gold Mining Firms?" Journal of Economic Geography, February, lbp064.

Vogel, David. 2003. "The Hare and the Tortoise Revisited: The New Politics of Consumer and Environmental Regulation in Europe.” British Journal of Political Science 33 (4): 557-580.

Walker, Helen, Lucio Di Sisto, and Darian McBain. 2008. "Drivers and Barriers to Environmental Supply Chain Management Practices: Lessons from the Public and Private Sectors." Journal of Purchasing and Supply Management, Practice Makes Perfect: Special Issue of Best Papers of the 16th Annual IPSERA Conference 2007, 14 (1): 69-85.

Wang, Hua, and Yanhong Jin. 2002. Industrial Ownership and Environmental Performance: Evidence from China. World Bank Publications.

- 2006. "Industrial Ownership and Environmental Performance: Evidence from China." Environmental and Resource Economics 36 (3): 255-73.

Wang, Hua, Nlandu Mamingi, Benoit Laplante, and Susmita Dasgupta. 2003. "Incomplete Enforcement of Pollution Regulation: Bargaining Power of Chinese Factories." Environmental and Resource Economics 24 (3): 245-62.

Wang, Hua, and David Wheeler. 2005. "Financial Incentives and Endogenous Enforcement in China's Pollution Levy System.” Journal of Environmental Economics and Management 49 (1): 174-96.

Xu, Chenggang. 2011. "The Fundamental Institutions of China's Reforms and Development." Journal of Economic Literature 49 (4): 1076-1151.

Yang, Xin, and Canfei He. 2015. "Do Polluting Plants Locate in the Borders of 
Jurisdictions? Evidence from China." Habitat International 50 (December): 140-48. Zhan, Xueyong, Carlos Wing-Hung Lo, and Shui-Yan Tang. 2014. "Contextual Changes and Environmental Policy Implementation: A Longitudinal Study of Street-Level Bureaucrats in Guangzhou, China." Journal of Public Administration Research and Theory 24 (4): 1005-35.

Zhang, Bing, Jun Bi, Zengwei Yuan, Junjie Ge, Beibei Liu, and Maoliang Bu. 2008. "Why Do Firms Engage in Environmental Management? An Empirical Study in China." Journal of Cleaner Production 16 (10): 1036-45.

Zhang, Jing, and Xiaolan Fu. 2008. "FDI and Environmental Regulations in China." Journal of the Asia Pacific Economy 13 (3): 332-53.

Zhao, X. B., and L. Zhang. 1999. "Decentralization Reforms and Regionalism in China: A Review." International Regional Science Review 22 (3): 251-81.

Zhu, Shengjun, Canfei He, and Ying Liu. 2014. "Going Green or Going Away:

Environmental Regulation, Economic Geography and Firms' Strategies in China's Pollution-Intensive Industries.” Geoforum 55 (August): 53-65. 
Table A1 Definition of variables and descriptive statistics

\begin{tabular}{|c|c|c|c|c|c|c|c|}
\hline Variable & & Definitions & Data Source & MEAN & MAX & MIN & SD \\
\hline \multirow{4}{*}{ Firm dynamics } & Entry & $\begin{array}{l}\text { Entry takes the value of } 1 \text { if a firm is an entrant and } 0 \\
\text { otherwise }\end{array}$ & ASIF & 0.327 & 1.000 & 0.000 & 0.469 \\
\hline & Exit & Exit takes the value of 1 if a firm exits and 0 otherwise & ASIF & 0.119 & 1.000 & 0.000 & 0.324 \\
\hline & Employment & Employment change of a firm & ASIF & 0.006 & 512.203 & -522.371 & 0.769 \\
\hline & $T F P$ & TFP change of a firm & ASIF & 0.030 & 16.424 & -18.543 & 0.949 \\
\hline \multirow{2}{*}{$\begin{array}{l}\text { Environmental } \\
\text { regulation }\end{array}$} & $E R$ & $\begin{array}{l}\text { The percentage of industrial } \mathrm{SO}_{2} \text { meeting standard for } \\
\text { emission }\end{array}$ & $\begin{array}{l}\text { China Environmental } \\
\text { Statistical Yearbook }\end{array}$ & 0.742 & 0.996 & 0.000 & 0.324 \\
\hline & $P I$ & $\begin{array}{l}\text { The share of firms that have been included in the } \\
\text { KNMSPF air pollution list }\end{array}$ & KNMSPF & 0.011 & 1.000 & 0.000 & 0.085 \\
\hline \multirow{4}{*}{$\begin{array}{l}\text { Firm } \\
\text { Characteristics }\end{array}$} & SIZE & The number of employees of a firm & ASIF & 0.246 & 569.67 & 0 & 1.309 \\
\hline & $S O E$ & $\begin{array}{l}\text { SOE takes the value of } 1 \text { if the largest share of a firm's } \\
\text { paid-in capital is state-owned, and } 0 \text { otherwise. }\end{array}$ & ASIF & 0.064 & 1.000 & 0.000 & 0.244 \\
\hline & FOE & $\begin{array}{l}\text { FOE takes the value of } 1 \text { if the largest share of a firm's } \\
\text { paid-in capital is foreign-owned, and } 0 \text { otherwise. }\end{array}$ & ASIF & 0.161 & 1.000 & 0.000 & 0.368 \\
\hline & $P O E$ & $\begin{array}{l}\text { POE takes the value of } 1 \text { if the largest share of a firm's } \\
\text { paid-in capital is privately-owned, and } 0 \text { otherwise. }\end{array}$ & ASIF & 0.722 & 1.000 & 0.000 & 0.448 \\
\hline \multirow{2}{*}{$\begin{array}{l}\text { Local } \\
\text { government } \\
\text { intervention }\end{array}$} & SUBSIDY & $\begin{array}{l}\text { The ratio of the value of government subsidies a firm has } \\
\text { received to the firm's total output value }\end{array}$ & ASIF & 0.008 & 3728.000 & -4.337 & 3.425 \\
\hline & PARK & $\begin{array}{l}\text { Park takes the value of } 1 \text { if a firm is located in industrial } \\
\text { parks and } 0 \text { otherwise. }\end{array}$ & ASIF & 0.151 & 1.000 & 0.000 & 0.358 \\
\hline \multirow{2}{*}{$\begin{array}{l}\text { Control } \\
\text { variables }\end{array}$} & $L Q$ & An industrial sector's location quotient & ASIF & 3.586 & 2110.428 & 0.000 & 15.724 \\
\hline & $L A B$ & The average labor cost in an industrial sector in a city & & 12.917 & 935 & 0 & 12.410 \\
\hline
\end{tabular}




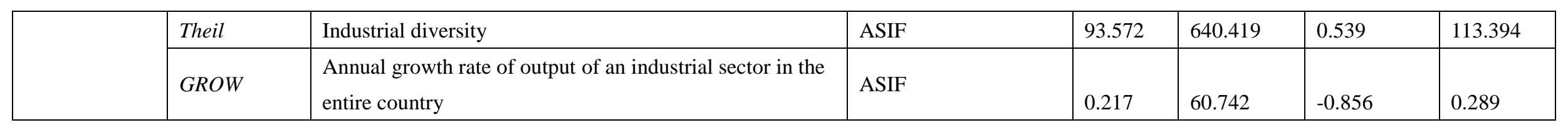


Table A2 Empirical results

\begin{tabular}{|c|c|c|c|c|c|c|c|c|}
\hline & $\begin{array}{c}(1) \\
\text { Entry }\end{array}$ & $\begin{array}{c}(2) \\
\text { Exit }\end{array}$ & $\begin{array}{c}\text { (3) } \\
\text { growth }\end{array}$ & $\begin{array}{l}(4) \\
\text { TFP }\end{array}$ & $\begin{array}{c}(5) \\
\text { Entry }\end{array}$ & $\begin{array}{c}(6) \\
\text { Exit }\end{array}$ & $\begin{array}{c}(7) \\
\text { growth }\end{array}$ & $\begin{array}{l}(8) \\
\text { TFP }\end{array}$ \\
\hline$E R * P I$ & $-0.0460^{* * *}$ & $0.0144^{* * * *}$ & $0.0308^{* * *}$ & $-0.0324^{* * *}$ & $0.0117^{*}$ & $0.0452^{* * * *}$ & $-0.0234^{*}$ & $-0.127^{* * *}$ \\
\hline$E R * P I * S I Z E$ & & & & & $0.010^{* * *}$ & $0.004^{* * *}$ & $0.0904^{* * *}$ & -0.003 \\
\hline$E R * P I * S O E$ & & & & & $-0.0280^{* * *}$ & $-0.0901^{* * *}$ & $-0.2859^{* * *}$ & $0.225^{* * *}$ \\
\hline$E R * P I * F O E$ & & & & & $-0.0568^{* * *}$ & $-0.0161^{*}$ & -0.0214 & $0.352^{* * *}$ \\
\hline$E R * P I * P O E$ & & & & & $-0.0867^{* * *}$ & $-0.0304^{* * *}$ & -0.0529 & $0.0862^{* * *}$ \\
\hline$E R * P I * P A R K$ & & & & & $0.0364^{* * *}$ & $-0.0241^{* *}$ & $0.0970^{* * * *}$ & -0.0057 \\
\hline$E R * P I * S U B S I D Y$ & & & & & $-0.335^{* * *}$ & $0.0727^{* * *}$ & -0.0469 & $-1.151^{* * *}$ \\
\hline SIZE & $-0.108^{* * *}$ & $-0.0565^{* * *}$ & $-0.0122^{* * *}$ & $0.0572^{* * *}$ & $-0.142^{* * *}$ & $-0.0664^{* * *}$ & $-0.0390^{* * *}$ & $0.0587^{* * *}$ \\
\hline SUBSIDY & -0.0005 & $0.0002^{* * *}$ & -0.0066 & $-0.877^{* * *}$ & -0.0005 & $0.0002^{* * *}$ & -0.00104 & $-0.863^{* * *}$ \\
\hline$T F P_{t-1}$ & & & $0.0119^{* * *}$ & $-0.412^{* * *}$ & & & $0.0120^{* * *}$ & $-0.412^{* * *}$ \\
\hline PARK & $0.0065^{* * *}$ & $-0.0195^{* * *}$ & $0.0984^{* * *}$ & 0.0007 & $0.0048^{* * * *}$ & $-0.0189^{* * *}$ & $0.0938^{* * * *}$ & 0.0024 \\
\hline$L Q$ & $-0.089^{* * *}$ & $-0.0850^{* * *}$ & 0.0010 & -0.00411 & $-0.0855^{* * *}$ & $-0.0821^{* * *}$ & 0.0049 & -0.00623 \\
\hline Theil & $-0.0002^{* * * *}$ & $0.00009^{* * * *}$ & $0.0094^{* *}$ & $-0.0001^{* * *}$ & $-0.0002^{* * *}$ & $0.00009^{* * *}$ & $0.0103^{* *}$ & $-0.0001^{* * *}$ \\
\hline$L A B$ & $-0.001^{* * *}$ & -0.00002 & $-0.0011^{* * *}$ & $0.004^{* * *}$ & $-0.0001^{* * *}$ & -0.0003 & $-0.0912^{* * *}$ & $0.00407^{* * *}$ \\
\hline GROW & $0.122^{* * *}$ & $0.0347^{* * *}$ & 0.02044 & $0.0342^{* * *}$ & $0.119^{* * *}$ & $0.0350^{* * *}$ & -0.0382 & $0.0352^{* * *}$ \\
\hline$S O E$ & Included & Included & Included & Included & $-0.0369^{* * *}$ & $0.0470^{* * *}$ & $0.0120^{* * *}$ & $-0.138^{* * *}$ \\
\hline$F O E$ & Included & Included & Included & Included & $0.0414^{* * *}$ & $-0.0365^{* * *}$ & $0.0170^{* * *}$ & $-0.0387^{* * *}$ \\
\hline POE & Included & Included & Included & Included & $0.0895^{* * *}$ & $-0.0207^{* * *}$ & 0.0029 & -0.0058 \\
\hline Industry & Included & Included & Included & Included & Included & Included & Included & Included \\
\hline Province & Included & Included & Included & Included & Included & Included & Included & Included \\
\hline Year & Included & Included & Included & Included & Included & Included & Included & Included \\
\hline _cons & $0.214^{* * *}$ & $0.157^{* * *}$ & $-0.2731^{* * * *}$ & $1.266^{* * *}$ & $0.113^{* * *}$ & $0.125^{* * *}$ & -0.5927 & $1.273^{* * *}$ \\
\hline
\end{tabular}




\begin{tabular}{l|cccc|cccc}
\hline$N$ & 1174871 & 1452688 & 850862 & 621655 & 1174892 & 1452712 & 850864 & 621655 \\
$R^{2}$ & 0.033 & 0.023 & 0.003 & 0.239 & 0.035 & 0.023 & 0.012 & 0.239 \\
\hline
\end{tabular}

